\title{
Evaluating the transition to green economy in Kazakhstan: A synthetic control approach
}

\section{Galiya Sansyzbayeva}

Department of Management, Higher School of Economics and

Business, Al-Farabi Kazakh National University,

Republic of Kazakbstan

gns1981@,mail.ru

ORCID 0000-0001-8081-5151

\section{Zhansaya Temerbulatova}

Department of Economics, Higher School of Economics and Business, Al-Farabi Kazakh National University, Republic of Kazakhstan

t.zhansaya.s@mail.ru

ORCID 0000-0002-3205-0948

\section{Zhidebekkyzy Aknur}

Higher School of Economics and Business, Al-Farabi Kazakh

National University, Republic of Kazakhstan

aknur.zb@gmail.com

ORCID 0000-0003-3543-547X

\section{Ashirbekova Laura}

Department of Management, Higher School of Economics and

Business, Al-Farabi Kazakh National University,

Republic of Kazakbstan

turar200480@mail.ru

ORCID 0000-0003-0377-7854

Abstract. In the modern world, due to the growing environmental threats, each state has the task of reducing the anthropogenic impact on the environment. Many countries, especially developed ones, have been seriously studying this problem and are finding solutions. However, in developing countries the situation is different, along with the growth of the economy, environmental damage is growing. The purpose of this article is to evaluate the impact of the existing measures aimed at reducing emissions and to assess the readiness of the regions in Kazakhstan for the transition to green economy. In the article, the effect of adoption of the Concept of transition to green economy on $\mathrm{CO}_{2}$ emissions in Kazakhstan was assessed. Using the synthetic control method, the panel data of

Received:

June, 2019

1st Revision: September, 2019

Accepted: February, 2020

DOI:

10.14254/2071 8330.2020/13-1/21 
Kazakhstan and 30 control countries for 2003-2018 were evaluated. As a result of constructing a counterfactual, it is revealed that the effect of the Concept can be traced in Kazakhstan, however, the trend of annual emissions' increase remains. The second part of the analysis covers the assessment of the potential of the regions in Kazakhstan for the transition to green economy through assessing the decoupling effect of GRP from pollutant emissions into the atmosphere. For this assessment, the data as of 2005-2018 for 14 regions and 2 cities of republican significance in Kazakhstan are used. The pair correlation between gross regional product and 2 types of environmental pollution is calculated. Based on the results of correlation assessment, the regions were selected that showed the best and the worst results and a detailed analysis of these regions was carried out based on a regression model. The results show a heterogeneous situation in the regions of Kazakhstan, as only in 7 regions out of 16 the effect of decoupling was revealed (high one - only in 4 regions). The authors propose measures to improve the situation in individual regions and in the country as a whole.

Keywords: synthetic control method, the Concept of transition to green economy, $\mathrm{CO}_{2}$ emissions, decoupling effect, Kazakhstan regions, green economy, economic growth, environmental pollution, emissions of pollutants.

JEL Classification: Q01, Q53, Q56, C51

\section{INTRODUCTION}

In connection with the growth and deepening of environmental problems in the world, it is very important to control the environmental impact of human activities. This should be one of the highest priorities of every contemporary state. At the end of the 20th century, a new direction in economic science - the green economy - was formed, in the framework of which it is believed that economy is a dependent component of natural environment within which it exists and is part of it. First of all, green economy is aimed at the economical consumption of those resources that are currently prone to depletion and the rational use of inexhaustible resources, as well as clean and "green" production, which does not emit emissions into the environment. Reducing total emissions while maintaining high rates of economic development underlies the concept of sustainable development.

In accordance with the global desire for comprehensive and sustainable growth, Kazakhstan adopted the Concept of transition to green economy in 2013. Transition to green growth is a necessary priority for Kazakhstan, since the country's economic development is currently largely focused on extractive industries and export of raw materials. At the same time, in most sectors of the economy there are relatively high levels of energy intensity and pollution, as well as low energy efficiency. Moreover, Kazakhstan is the state with the largest greenhouse gas emissions in Central Asia.

Carbon dioxide $\left(\mathrm{CO}_{2}\right)$ makes up the largest share of greenhouse gas emissions. This article discusses the effect of the Concept of transition to green economy on changes in $\mathrm{CO}_{2}$ emissions into the atmosphere using the synthetic control method which allows us assess the situation in the absence of the Concept.

Despite the fact that rapid economic growth can be achieved through aggressive consumption of limited resources, ignoring environmental pollution and environmental costs or by implementing other irrational methods, this expansion is ultimately doomed to failure, eliminating any positive successes or 
achievements as evidenced by numerous examples around the world. (Liao et al., 2019; Savitz, Gavriletea, 2019) Therefore, the next step in the analysis is evaluating the decoupling effect by regions of Kazakhstan. Decoupling effect is the phenomenon, when economy grows, and environmental indicators do not deteriorate. Transition to sustainable development on the principles of green economy, achieving the effect of decoupling, should be a priority. The growth rate of achieving social and economic progress should be accompanied by low rates of resource consumption and reduction of environmental degradation.

The history of mankind in the recent centuries has shown an increase in prosperity with an absolute increase in resource consumption and environmental pollution. The twentieth century significantly advanced human civilization on the basis of scientific and technological progress, but the environmental charge for such growth was high (Bobylev et al., 2012). Today, environmental issues have become global and threaten all the humanity. To preserve the environment, each country is forced to switch to green economy, that is, take into account not only economic growth indicators, but also try to reduce the damage to the environment.

So the purpose of this article is to assess the impact of existing measures aimed at reducing the environmental impact and analysis of the situation in the context of the regions in Kazakhstan.

The rest of the article is organized as follows. Section 2 discusses the existing literature; section 3 discusses the concept of decoupling effect and assessment methodology. Section 4 presents the results of the assessment of the regions in Kazakhstan, and discusses the reasons for the presence / absence of the decoupling effect in several regions of the country. Section 5 presents the conclusions.

\section{LITERATURE REVIEW}

Today, the transition to a green economy is a priority for every state. A study by Mukhtarova et al. (2016) considers technologies and innovations as a driving force in the transition to a green economy, and examines existing practices and positive experiences of developed countries that other countries can adapt for themselves.

Yu et al. (2019) evaluated the effect of the low-carbon pilot initiative (LCPI) on emissions from largest energy consumer and carbon source - China. Using synthetic control, the result showed that carbon emissions in Guangdong were reduced by about $10 \%$ due to the introduction of LCPI. The authors propose introducing this initiative in other provinces of the country.

Using this method, Jardon et al. (2020) investigated the effects of the PetroCaribe energy subsidy program. As a result, it was revealed that PetroCaribe had a positive impact on economic growth in most participating countries; however, this economic boom was not followed by an improvement in social development, also there wasn't a significant effect on the trend of $\mathrm{CO}_{2}$ emissions per capita.

For the formation of a green economy, the achievement of a decoupling effect is critical. In the vocabulary of scientists and politicians, the term "decoupling" has recently become generally used; international organizations devote much attention to it. Thus, in the Report of the Joint UNECE / OECD / Eurostat Working Group on Statistics for Sustainable Development, the achievement of the decoupling effect between economic growth and environmental impact is identified as one of the seventeen key indicators for the transition to sustainable development (UN, 2008).

Moreau \& Vuille (2018), Moreau et al. (2019) see the decoupling of economic growth from energy consumption as an essential aspect of energy security. The article explores factors that affect energy consumption, such as structural changes, economic growth and measures to improve energy efficiency, energy use in trade. As a result of the study, it was concluded that the implementation of an effective energy efficiency policy that takes into account energy efficiency remains a priority for each state. 
The relationship between renewable energy sources, $\mathrm{CO}_{2}$ emissions and GDP is confirmed on the basis of econometric models using panel data from 1995 to 2015 of the EU candidate countries in a study by Bilan et al. (2019). The authors conclude that the development of effective measures to stimulate the introduction of renewable energy sources is necessary to reduce anthropogenic impact on environment (in particular, $\mathrm{CO}_{2}$ emissions reduction) without decreasing in economic growth.

In paper by Mikayilov et al. (2018) conducted an econometric analysis using a cointegration approach with time-varying coefficients to estimate the elasticity of $\mathrm{CO}_{2}$ emissions relative to GDP of 12 European countries. In the 8 studied countries, a relative decoupling effect is observed, which indicates that these countries have taken seriously the issue of reducing air emissions after the Kyoto Protocol and the Paris Agreement, in the other 4 countries the elasticity exceeds unity. Also in a study by Bluszcz (2018), Pearson's correlation coefficient between emissions and economic growth proved that the countries of the European Union: Germany, the UK, France, Italy, Poland, Spain, Sweden and the Netherlands achieved a decoupling effect.

German Development Institute (2009) explains the presence of decoupling in developed countries according to the Kuznets curve. By analogy with the hypothesis developed by Simon Kuznets, during economic growth, income inequality first increases, then equalizes, and finally decreases, in this case, a similar "inverted-U" relationship is considered for the relationship between socio-economic development and the depletion of natural resources. This means that after a turning point (a certain level of per capita income) is reached, a further increase in welfare will be separated from additional environmental burdens. Thus, decoupling can be considered as an automatic or "natural" process that occurs as the economy grows.

Also, on the basis of the concept of the Environmental hypothesis, Vasylieva et al. (2019) examined the relationship between the economic (GDP growth), social (corruption index) and environmental (greenhouse gas emissions and renewable energy consumption) aspects of sustainable development. Using panel data from the EU and Ukraine, it was found that an increase in renewable energy and an increase in the corruption control index lead to a decrease in greenhouse gases. Kuznets Curve

Based on the foregoing, there is a difference between the effect of decoupling in developed and developing countries. Wu et al. (2018) based on the OECD decoupling factor model, Tapio elastic analysis method, and the IGTX decoupling model proved that strong decoupling is observed in developed countries and slightly increases their stabilization, while developing countries show a weak decoupling, which varies significantly and does not have regularity.

However, a study by Akizu-Gardoki et al. (2018) shows that decoupling is not a phenomenon characteristic only of developed countries due to improved energy efficiency, but also occurs in countries with a low human development index and low energy consumption.

In particular, in Kazakhstan, according to a study by Mukhtarova \& Zhidebekkyzy (2015), based on an expert survey, it was found that in all sectors of the economy there is an inefficient use of resources. This is the main barrier to the transition to a green economy. The authors recommend supporting R\&D and innovative activities aimed at increasing the resource intensity of production. In an article by Zhidebekkyzy et al. (2019) identified 21 barriers, the understanding of which will contribute to the development of organizational and economic mechanisms for the transition to sustainable development. Also Sansyzbaeva et al. (2016) note the importance of stimulating the use of science and technology, introducing high technologies, activating all business entities in the scientific and technical sphere for the transition to sustainable growth in the agricultural sector, one of the most promising sectors in Kazakhstan.

Jiborn et al. (2018) believe that environmental issues should be strictly regulated by state policy, and suggest using a positive example of Sweden and the UK to use a new bias indicator - a technology-adjusted emission balance embodied in trade at the state level. A study by Samarina et al. (2015) also noted the role of the state in modernizing the environmental and economic situation. By the example of mining regions 
of Russia, the underdeveloped institutional conditions for the development of a green economy have been proved and that today this is not an object of public administration.

Limareva (2013) believes that population growth on the planet also has a negative impact on the environment. According to UN forecasts, in 2050 the world's population will reach 9 billion people. In solving the problem of population growth on the planet, as the researchers point out, it is important to achieve the effect of decoupling, which is reflected in the anticipation of the GDP growth rate over the rate of energy resource consumption.

\section{METHODOLOGY}

The first stage of the analysis includes an assessment of the effect of the Concept of the transition to a green economy on $\mathrm{CO}_{2}$ emissions using the synthetic control method. The method is aimed at assessing the effects of the impact using a small number of cases as an example of modeling their quantitative indicators in a hypothetical situation where there was no impact.

Let $Y_{i t}^{0}$ be the outcome ( $\mathrm{CO}_{2}$ emissions) that would be observed for country $i$ (Kazakhstan) at time $t$ in the absence of the intervention (Concept of the transition to a green economy) for units $i=1, \ldots, J+1$ and time periods $t=1, \ldots, T$. Let $T_{0}$ be the intervention period, where $1 \leq T_{0} \leq T$. Let $Y_{i t}^{1}$ be the outcome observed for country $i$ at time $t$ when the country is exposed to the intervention between periods $T_{0}+1$ and $T$. Then, the treatment effect (the impact of the intervention) for country $i$ can be defined as $\tau_{i t}=Y_{i t}^{1}-Y_{i t}^{0}$. However, $Y_{i t}^{1}$ is observed and $Y_{i t}^{0}$ is not observed between $T_{0}+1$ and $T$. Thus, $Y_{i t}^{0}$, which is the counterfactual, must be estimated to find the impact of the intervention.

Abadie et al. (2010) show how to identify the treatment effect, $\tau_{i t}$, using the following model for potential outcomes:

$$
\begin{aligned}
& Y_{i t}^{0}=\delta_{t}+Z_{i} \theta_{t}+\lambda_{t} \mu_{i}+\varepsilon_{i t} \\
& Y_{i t}^{1}=\delta_{t}+\tau_{i t}+Z_{i} \theta_{t}+\lambda_{t} \mu_{i}+\varepsilon_{i t},
\end{aligned}
$$

where $Z_{i}$ is a vector of relevant observed covariates (either time-varying or time-invariant) that are not affected by the intervention, $\theta_{t}$ a vector of parameters, $\lambda_{t}$ an unknown common factor, $\mu_{i}$ a country-specific unobservable, $\varepsilon_{i t}$ a transitory shock with a zero mean, and $\tau_{i t}$ a dummy variable that takes the value 1 for the treated unit, and 0 otherwise.

Suppose that the first country (Kazakhstan), $i=1$, receives the treatment (Concept of the transition to a green economy) and the remaining $J$ countries, $i=2, \ldots, J+1$, do not. The proposed data-driven approach is to approximate $Y_{i t}^{0}$ by a weighted average of $Y_{i t}^{1}$, taking into account the covariates $Z$ for the pre-intervention period, $t \leq T_{0}$, such that:

$$
\begin{aligned}
Y_{1 t} & =\sum_{i=2}^{J+1} w_{i}^{*} Y_{i t} \\
Z_{1} & =\sum_{i=2}^{J+1} w_{i}^{*} Z_{i},
\end{aligned}
$$


where the weights, $w_{i}$, satisfy $\sum_{i=2}^{J+1} w_{i}=1$ and $w_{i} \geq 0$. These two assumptions for the weights make sure that there is no extrapolation of outcomes from the model. Finally, the treatment effect can be estimated using:

$$
\widehat{\tau_{l t}}=Y_{1 t}-\sum_{i=2}^{J+1} w_{i}^{*} Y_{i t} \text { for } t=T_{0}+1, \ldots, T
$$

The main idea here is that the synthetic control imitates the counterfactual of the treated country that would have been observed in the absence of the intervention using the weighted average of all control countries. For the optimal choice of $W^{*}$, consider $X_{1}=\left(Z_{1}, Y_{11}, \ldots, Y_{1 T_{0}}\right)$ to be the vector of preintervention characteristics for country $i=1$, and $X_{0}=\left(Z_{j}, Y_{j t}, \ldots, Y_{j T_{0}}\right)$ to be the matrix of the same characteristics for the control units $j \in[2, j+1]$. Then the vector $W^{*}$ is chosen to minimize the distance between $X_{1}$ and $X_{0} W$, following:

$$
\begin{aligned}
\min _{W}\left\|X_{1}-X_{0} W\right\|_{v} & =\min _{W(V)} \sqrt{\left(X_{1}-X_{0} W\right)^{\prime} V\left(X_{1}-X_{0} W\right)} \\
\text { s.t. } w_{i} & \geq 0 \text { for } i=2, \ldots, J+1 \text { and } \sum_{i=2}^{J+1} w_{i}=1,
\end{aligned}
$$

where $V$ is a $k \times k$ symmetric and positive semi-definite matrix, which measures the relative importance of the pre-intervention characteristics included in $X$. Thus, $W$ is a function of the elements of $V$. The minimization problem above provides a solution for $W^{*}\left(V^{*}\right)$ that minimizes the pre-intervention Root Mean Square Prediction Error (RMSPE) of the outcome over the control period. Thus, the accuracy of the approximation depends on the minimization problem, which is satisfied with a lower RMSPE. In other words, the SCM estimates the unobserved counterfactual as a weighted average of the outcomes of the control countries, with weights chosen to approximate the pre-intervention characteristics of the affected country (Aytug et al., 2017).

When choosing control countries, Abadie and Gardeazabal (2003) proposed limiting the set of potential control countries - the donor pool, creating a selection criterion. In our case, 30 donor pool countries were selected, in which $\mathrm{CO}_{2}$ emissions in 2003 were in the range from 100 to $500 \mathrm{Mt} /$ year according to EDGARv5.0 Report (Emissions Database for Global Atmospheric Research) (2019) prepared by EU Science Hub of European Commission.

The analysis is based on a panel dataset spanning 31 countries over the period 2003-2018 at an annual frequency. Thus, the time period has sufficient coverage before and after the adoption of the Concept of transition to a green economy for empirical analysis. The global dataset provides a rich basis to form a donor pool for the weight-selection procedure in the synthetic control estimation. Dependent variable in the model is $\mathrm{CO}_{2}$ emissions (Mt/year), the independent variables are as follows:

- GDP per capita (current US\$);

- GDP growth (\%);

- Agriculture value added ( $\%$ of GDP);

- Industry value added (\% of GDP);

- Service value added ( $\%$ of GDP);

- Urban population ( $\%$ of total population).

All data of independent variables were taken from World Development Indicators of World Bank. The summary statistics are available in the Table 1. 
Descriptive statistics

\begin{tabular}{|l|c|c|c|c|}
\hline Variable & Mean & Std. Dev. & Min & Max \\
\hline lnCO2emissions & 5,334 & 0,599 & 3,644 & 6,328 \\
\hline lnGDPpercapita & 9,104 & 1,297 & 5,982 & 11,351 \\
\hline GDPgrowth & 3,751 & 5,114 & $-33,101$ & 54,158 \\
\hline Agrivalueadded & 7,283 & 7,368 & 0,094 & 33,827 \\
\hline Indvalueadded & 33,369 & 13,551 & 16,898 & 81 \\
\hline Servvalueadded & 53,145 & 11,094 & 18,8 & 71,611 \\
\hline Urbanpopulation & 69,159 & 19,013 & 26,092 & 100 \\
\hline
\end{tabular}

Note: calculated by authors based on the data EDGARv5.0 Report and World Development Indicators of World Bank

The second stage of analysis is evaluating the decoupling effect between volume of production and environmental pollution by regions of Kazakhstan. Since the achievement of the decoupling effect is the basis for the transition to a green economy and sustainable development of the region. There are two types of decoupling (Stamm et al., 2009):

1. Relative, in which production volumes increase, but the rate of environmental pollution grows noticeably slower.

2. Absolute, in which production volumes increase, and the rate of environmental pollution decreases.

The study proposes to determine the effect of decoupling by calculating the pair correlation coefficient between the gross regional product and 2 types of environmental pollution (emissions of solid pollutants and emissions of liquid and gaseous pollutants into the atmosphere). In the case when a change in one of the quantities does not lead to a regular change in the other quantity, we can talk about the absence of a correlation between these quantities. The correlation coefficient can vary from +1 to -1 . If, with an increase in the value of one quantity, a decrease in the values of another quantity occurs, then their correlation coefficient is negative. In the case when an increase in the values of the first object of observation leads to increases in the value of the second object, then we can talk about a positive coefficient. In our case, if the correlation coefficient is positive, then there is no decoupling effect, that is, economic growth entails a deterioration of environmental indicators. If the correlation coefficient is negative, a mismatch of economic and environmental indicators is observed. If, with economic growth, environmental impact indicators decrease or their growth rate is lower than economic growth, then the effect of decoupling is observed.

Applying the Cheddock scale for the values of the pair correlation coefficients between the gross regional product and atmospheric air pollution indicators, we can get very low, low, average and high decoupling effect.

The assessment was carried out for 14 regions and 2 cities of republican significance of the Republic of Kazakhstan over the past 14 years (2005-2018).

For a detailed analysis of regions in which there is no decoupling effect, it is proposed to construct a linear regression, where the dependent variable $(\mathrm{Y})$ will be the emissions into the atmosphere, and the independent variable $(\mathrm{X})$ will be the output of a certain industry. Linear regression will look like this:

$$
Y_{t}=a+b X_{t}
$$


For construction of linear regression, we should assess of its parameters « $a »$ and « $b$ » and give their economic interpretation. Parameter « $a »$ shows the value of $\mathrm{Y}$ at $\mathrm{X}=0$. The parameter « $b$ » is a regression coefficient and shows the average change in the result when the factor changes by one unit (Yashalova, 2015; Kisel'áková et al., 2019).

The determination coefficient is important while assessing the quality of the constructed model, it shows how much of the variability of the observed variable can be explained using the constructed model. In this study, the coefficient of determination shows how many percent of cases a change in the production volume of a particular industry leads to a change in the volume of emissions into the atmosphere.

Linear regression models are built for a number of regions of Kazakhstan, in which economic growth is certainly accompanied by a negative impact on the environment.

All data for estimating pair correlation and constructing linear regression models was taken from the official website of the Committee on Statistics of the Ministry of National Economy of the Republic of Kazakhstan.

\section{RESULTS AND DISCUSSION}

At first, this section presents the results of the assessment of impact of the Concept of the transition to a green economy on $\mathrm{CO}_{2}$ emissions in Kazakhstan using the synthetic control method. Evaluation was performed using synth command in STATA.

Although the Concept was adopted in 2013, it entered into force in 2014, so the treatment period was selected as 2014.

Table 2

Synthetic control group composition in KAZ-EAEU analysis

\begin{tabular}{|l|c|}
\hline Country & Weight \\
\hline United Arab Emirates & 0,39 \\
\hline Turkey & 0,376 \\
\hline Brazil & 0,122 \\
\hline Vietnam & 0,112 \\
\hline
\end{tabular}

Table 2 reports the list of potential counterfactual units for Kazakhstan, together with the corresponding average weights obtained using the synthetic algorithm, where weights are chosen so that the synthetic counterfactual unit best resembles the characteristics of the corresponding unit in question during the period 2003-2013. These weights for those control countries are obtained as a result of the minimization problem described in equations (6) and (7). 


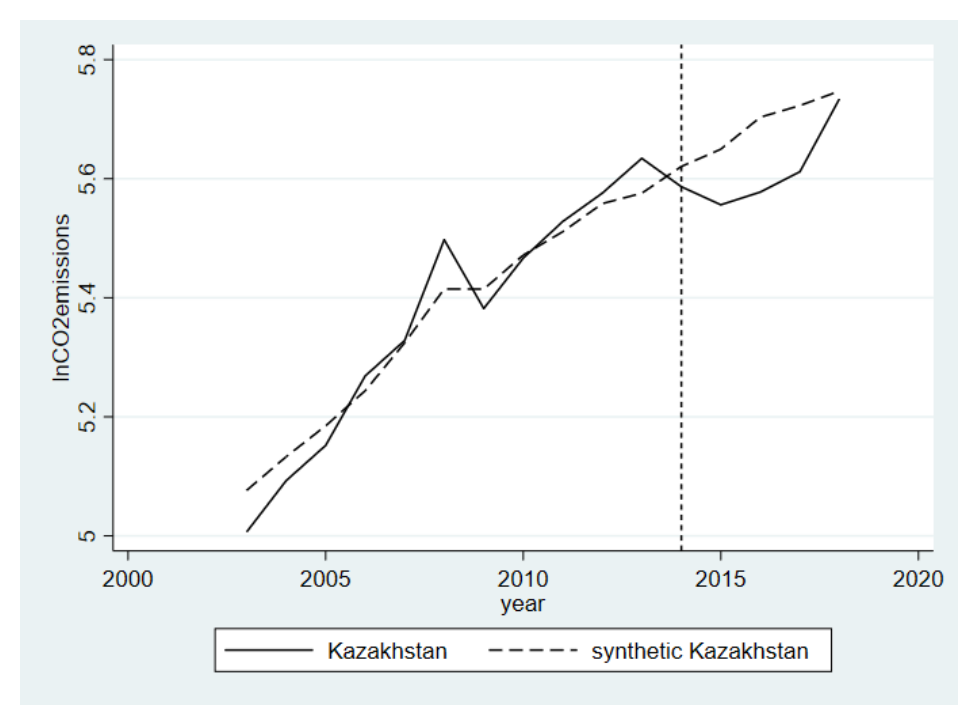

Figure 1. Synthetic counterfactual result for KAZ-EAEU

Figure 1 plots the dynamics of $\mathrm{CO}_{2}$ emissions of Kazakhstan and of the synthetic units over the period 2003-2018. The solid line displays actual values of emissions of Kazakhstan, while the dashed line represents the average value of emissions obtained from 4 synthetic counterfactuals, which were selected from 30 donor pool countries. The vertical dash line denotes the treatment year.

In the case of the pre-treatment period 2003-2013, the synthetic counterfactuals provide a good approximation of the units, and the synthetic (dashed line) and actual values (solid line) behave very similarly. After the treatment period, the series labelled 'synthetic Kazakhstan' shows what the estimated Kazakhstan's $\mathrm{CO}_{2}$ emissions would have been if the Concept of transition to green economy had not been adopted. From the figure, it is clear that the real volume of emissions is lower than the synthetic one, but tend to grow. This result suggests that $\mathrm{CO}_{2}$ emissions of Kazakhstan would have been higher without the adoption of the Concept.

It should be noted that pre-treatment outcomes fit well and close to zero. On the assumption of the root mean squared prediction error (RMSPRE) is equal to 0,043 , the results are robust and statistically significant.

Also to assess the significance of our estimates, we conduct a placebo tests as described in the work of Abadie et al. (2010) by iteratively applying the synthetic control method used to estimate the effect of adoption the Concept of transition to green economy in Kazakhstan to every other country in the donor pool. In each iteration we reassign in our data of bilateral trade to one of the 30 control countries, shifting Kazakhstan to the donor pool. 


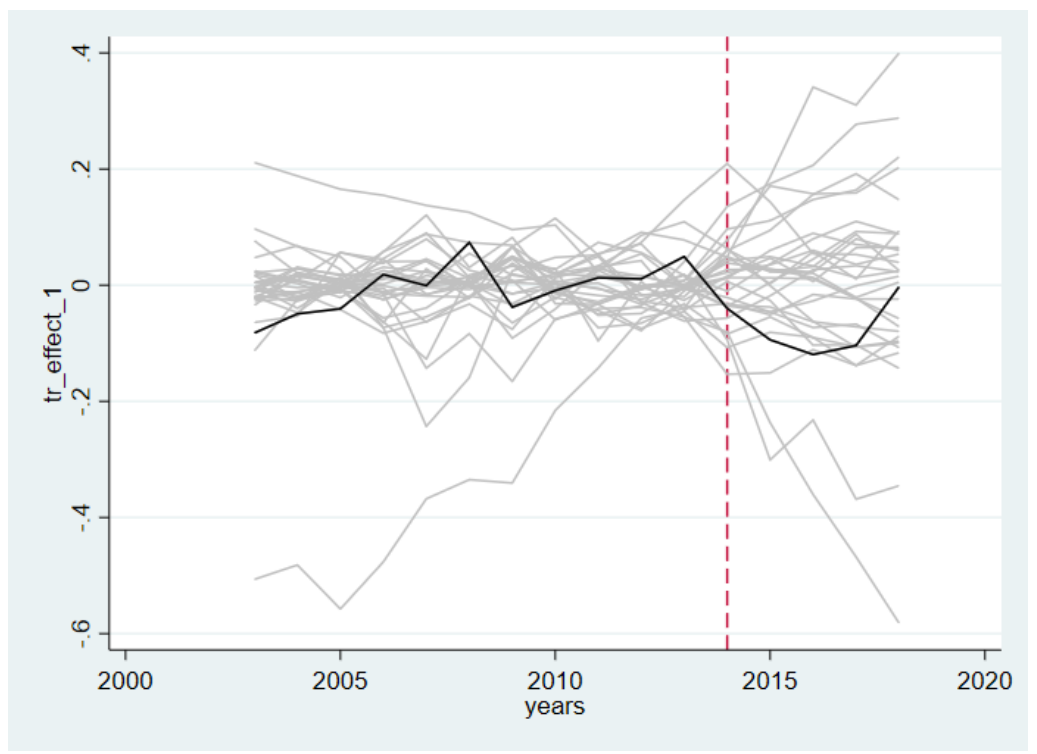

Figure 2. Placebo test results

Figure 2 displays the results for the placebo test. The gray lines represent the gap associated with each of the 30 runs of the test. That is, the gray lines show the difference in $\mathrm{CO}_{2}$ emissions of each country in the donor pool and its respective synthetic version. The black line denotes the gap estimated for Kazakhstan. Based on Figure 2, we can conclude that the results are significant and robust.

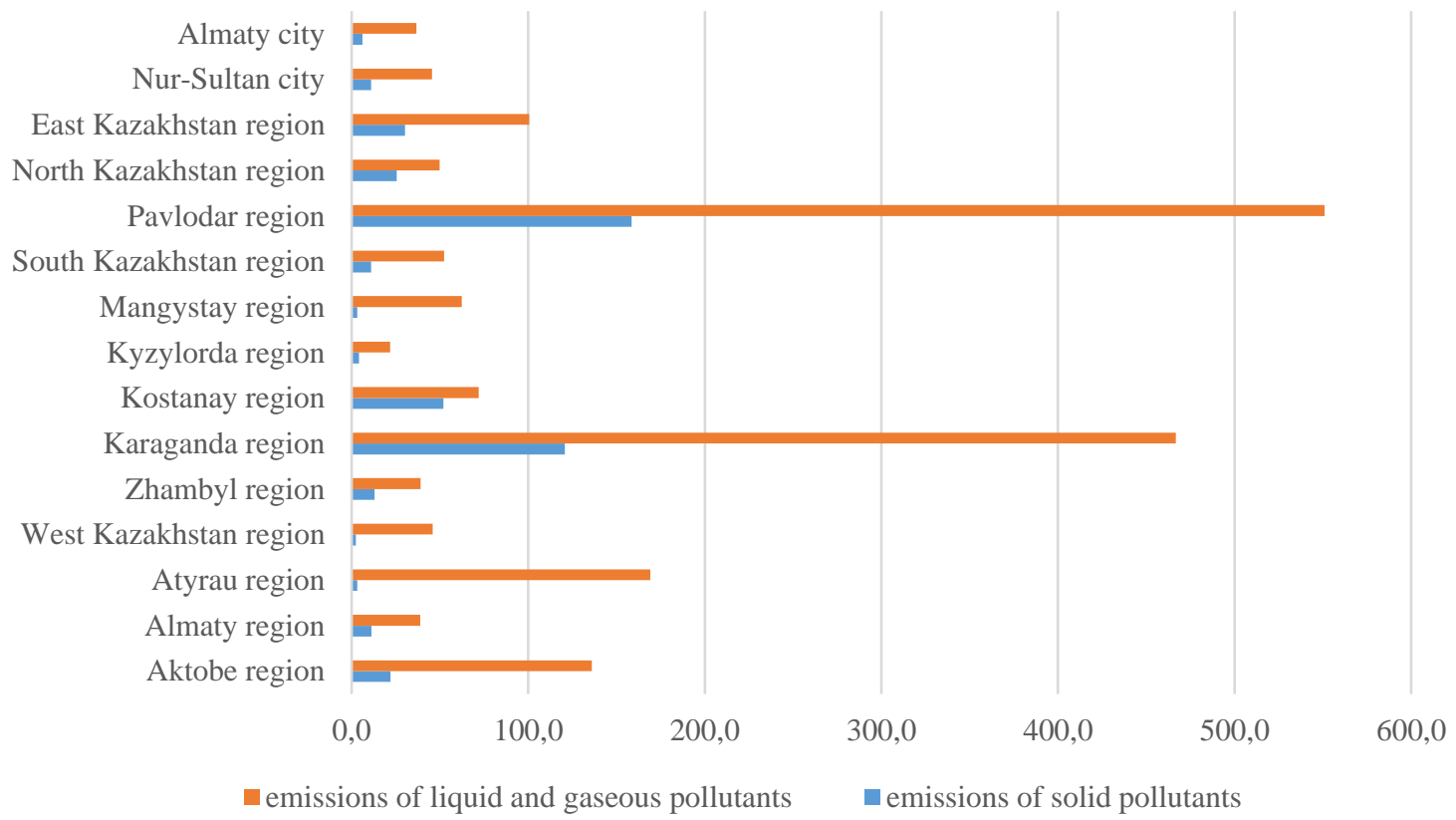

Figure 3. Emissions of pollutants into the atmosphere by regions of the Republic of Kazakhstan for 2018, thousand tons

Source: compiled by authors based on the data from the Committee on Statistics of the Ministry of National Economy of the Republic of Kazakhstan 
The first stage of the analysis showed that there is an effect from the adoption of the Concept of transition to a green economy in Kazakhstan, that is, $\mathrm{CO}_{2}$ emissions are less than they could be in the absence of the Concept, however, there is a tendency to increase emissions. For a detailed analysis of the problem, it is necessary to consider Kazakhstan by region. At the next stage of the analysis, we evaluate the decoupling effect between GRP and atmospheric emissions in the regions of Kazakhstan, which perfectly characterizes the region's potential for a transition to a green economy.

Before assessing of decoupling effect, it is advisable to show the volume of emissions of pollutants into the atmosphere in the context of regions.

In Kazakhstan, 2,447 million tons of pollutants were released into the air in $2018,79.2 \%$ of which are liquid and gaseous substances, and only 20.8\% are solid. As can be seen in Figure 3, there are the largest emissions in the Karaganda and Pavlodar regions. These industrial regions account for more than half $(53 \%)$ of all emissions from stationary sources.

Next, we consider the relationship between the production of industrial enterprises and their impact on the environment in the regions of the Republic of Kazakhstan. The following variables were considered as variables for determining the correlation coefficient: GRP of each region and emissions of pollutants into the atmosphere.

Table 3

Descriptive statistics

\begin{tabular}{|c|c|c|c|c|c|c|c|c|c|c|}
\hline \multirow[b]{2}{*}{ Region } & \multicolumn{5}{|c|}{$\begin{array}{c}\text { Emissions of pollutants into the } \\
\text { atmosphere }\end{array}$} & \multicolumn{5}{|c|}{ GRP } \\
\hline & Min & Mean & $\operatorname{Max}$ & St Dev & $\begin{array}{l}\mathrm{CoV} \\
(\%)\end{array}$ & Min & Mean & Max & St Dev & $\begin{array}{l}\mathrm{CoV} \\
(\%)\end{array}$ \\
\hline Akmola region & 44,00 & 81,00 & 105,70 & 15,454 & 20 & 196761,30 & 802360,90 & 1518059,40 & 430403,019 & 53 \\
\hline Aktobe region & 119,80 & 156,85 & 218,40 & 36,086 & 23 & 412959,40 & $\begin{array}{c}1659538,5 \\
0\end{array}$ & 2667044,20 & 703068,269 & 48 \\
\hline Almaty region & 43,40 & 66,30 & 74,70 & 10,295 & 17 & 322696,90 & $\begin{array}{c}1342181,7 \\
5\end{array}$ & 2500000,00 & 760398,993 & 56 \\
\hline Atyrau region & 89,40 & 108,40 & 177,00 & 30,113 & 25 & 808222,00 & \begin{tabular}{|c|}
3702487,4 \\
5 \\
\end{tabular} & 5969220,00 & $\begin{array}{c}1738127,46 \\
7 \\
\end{array}$ & 52 \\
\hline $\begin{array}{l}\text { West Kazakhstan } \\
\text { region }\end{array}$ & 41,50 & 48,90 & 76,40 & 10,020 & 19 & 401105,50 & $\begin{array}{c}1534170,6 \\
0\end{array}$ & 2285053,10 & 666571,755 & 48 \\
\hline Zhambyl region & 16,70 & 31,25 & 52,40 & 13,321 & 40 & 168554,80 & 696995,45 & 1314044,30 & 416958,351 & 59 \\
\hline Karaganda region & 572,60 & 651,30 & 1415,40 & 305,690 & 38 & 679805,90 & $\begin{array}{c}2417107,7 \\
5\end{array}$ & 4214432,00 & $\begin{array}{c}1143473,28 \\
2\end{array}$ & 49 \\
\hline Kostanay region & 91,60 & 110,20 & 124,00 & 8,978 & 8 & 322711,30 & \begin{tabular}{|c|}
1142476,9 \\
5 \\
\end{tabular} & 1787042,60 & 476968,497 & 45 \\
\hline Kyzylorda region & 26,00 & 31,15 & 40,00 & 3,762 & 12 & 242378,50 & $\begin{array}{c}1151971,4 \\
5 \\
\end{array}$ & 1683805,20 & 454474,912 & 45 \\
\hline Mangystay region & 61,70 & 65,65 & 88,30 & 7,423 & 11 & 432225,20 & $\begin{array}{c}1816368,0 \\
5\end{array}$ & 3274548,30 & 846431,560 & 49 \\
\hline $\begin{array}{l}\text { South Kazakhstan } \\
\text { region }\end{array}$ & 36,80 & 47,85 & 72,10 & 12,879 & 25 & 358008,70 & $\begin{array}{c}1690639,1 \\
5\end{array}$ & 3111409,80 & 996434,420 & 59 \\
\hline Pavlodar region & 542,70 & 589,75 & 709,30 & 49,611 & 8 & 384018,60 & $\begin{array}{c}1520534,2 \\
5\end{array}$ & 2339645,50 & 654591,91 & 48 \\
\hline $\begin{array}{l}\text { North Kazakhstan } \\
\text { region }\end{array}$ & 65,50 & 75,20 & 77,80 & 4,178 & 6 & 184672,30 & 673102,95 & 1085922,90 & 293586,431 & 47 \\
\hline $\begin{array}{l}\text { East Kazakhstan } \\
\text { region }\end{array}$ & 125,00 & 143,55 & 166,50 & 14,510 & 10 & 467510,00 & $\begin{array}{c}1716045,5 \\
0\end{array}$ & 3433300,00 & 955409,081 & 55 \\
\hline Nur-Sultan city & 43,70 & 56,45 & 65,10 & 8,029 & 14 & 711612,00 & $\begin{array}{c}2396126,2 \\
5 \\
\end{array}$ & 5765600,00 & $\begin{array}{c}1822885,94 \\
7 \\
\end{array}$ & 63 \\
\hline Almaty city & 11,00 & 15,10 & 43,50 & 14,033 & 61 & $\begin{array}{l}1497400,0 \\
0\end{array}$ & $\begin{array}{c}5288050,0 \\
0\end{array}$ & $\begin{array}{c}12302000,0 \\
0\end{array}$ & $\begin{array}{c}3671015,74 \\
3\end{array}$ & 60 \\
\hline
\end{tabular}

Source: calculated by authors based on the data from the Committee on Statistics of the Ministry of National Economy of the Republic of Kazakhstan

St Dev - standard deviation, $\mathrm{CoV}(\%)$ - coefficient of variation 
Table 3 presents some descriptive statistics. It can be seen that over the sample period the volatility of emissions was within somewhat acceptable ranges in Almaty city, Zhambyl and Karaganda regions (coefficient of variation smaller than 66\%). Whereas it was low for all other regions (coefficient of variation smaller than 33\%). Regarding GRP, the volatility is almost the same in many countries of the sample. The level of volatility of income is relatively higher in Nur-Sultan and Almaty cities.

The results of detecting the decoupling effect by regions are presented in Figure 4.

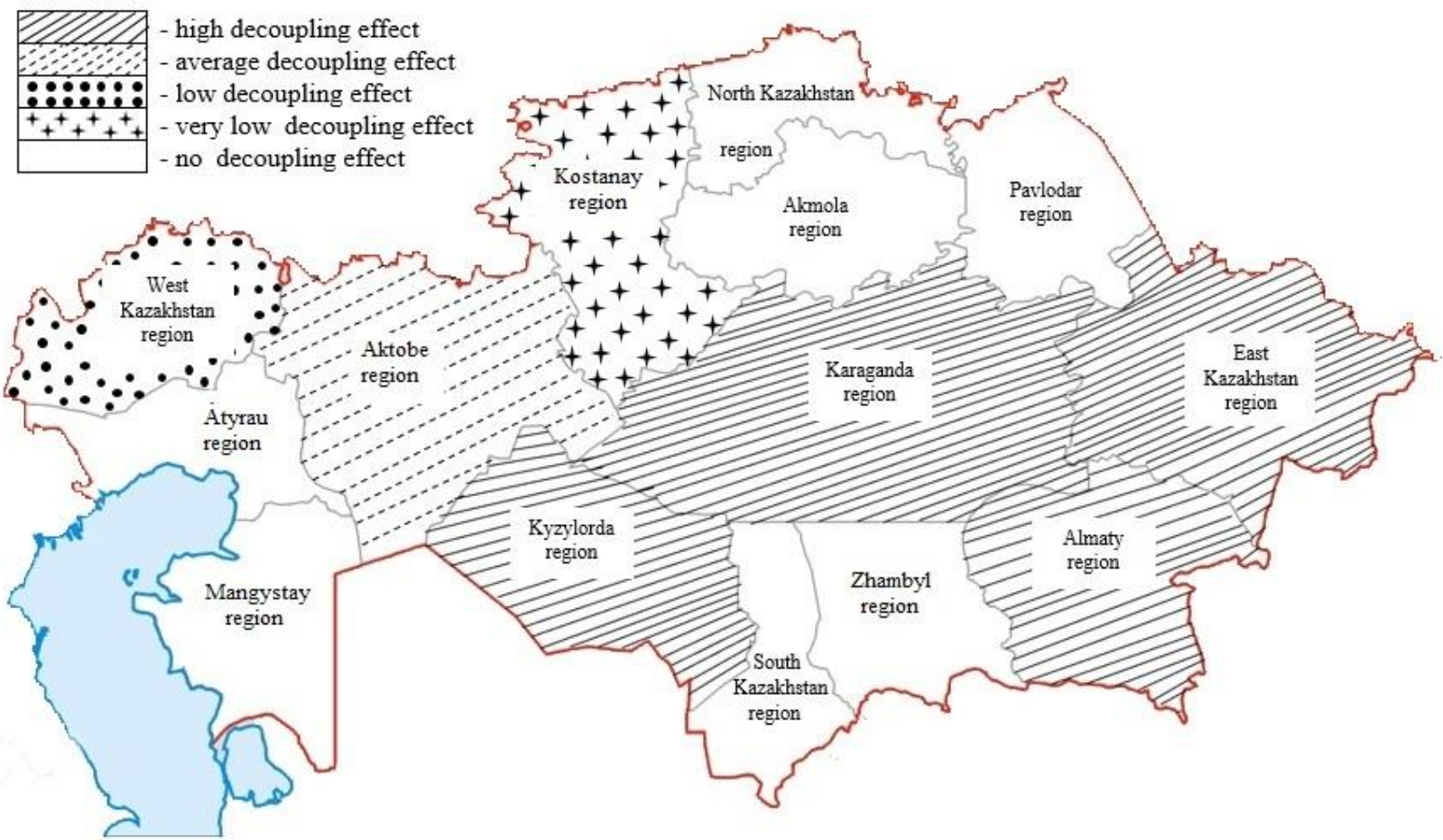

Figure 4. Identification of decoupling effect of pollutant emissions into the atmosphere in the context of the regions of Kazakhstan, 2005-2018

Source: compiled by authors

According to Figure 2, high level of decoupling effect was revealed in 4 regions of Kazakhstan, the average decoupling effect was determined in the Aktobe region, in the West Kazakhstan region the decoupling effect is low, in the Kostanay region it is very low, but there is still a positive trend. In most regions ( 7 regions and 2 cities of republican significance), the effect of decoupling is completely absent, that is, simultaneously with the growth of GRP, environmental damage is also increasing.

Atmospheric air is polluted by substances of different properties. Gaseous substances are known to be advantageous. The results of identifying the effect of decoupling in the regions of the Republic of Kazakhstan for two types of air pollution are presented in Table 2. 
Table 4

Decoupling effect in the regions of the Republic of Kazakhstan (2005-2018)

\begin{tabular}{|c|c|c|}
\hline Region & $\begin{array}{l}\text { Decoupling effect on emissions of } \\
\text { solid pollutants into the atmosphere }\end{array}$ & $\begin{array}{l}\text { Decoupling effect on emissions of liquid and } \\
\text { gaseous pollutants into the atmosphere }\end{array}$ \\
\hline Akmola region & 0,294 (missing) & 0,728 (missing) \\
\hline Aktobe region & 0,918 (missing) & $-0,619$ (average) \\
\hline Almaty region & $-0,957$ (very high) & $-0,509$ (average) \\
\hline Atyrau region & 0,801 (missing) & 0,842 (missing) \\
\hline West Kazakhstan region & 0,128 (missing) & $-0,408$ (average) \\
\hline Zhambyl region & 0,669 (missing) & 0,93 (missing) \\
\hline Karaganda region & $-0,949$ (very high) & $-0,765$ (high) \\
\hline Kostanay region & $-0,426$ (average) & 0,224 (missing) \\
\hline Kyzylorda region & 0,0001 (missing) & 0,934 (missing) \\
\hline Mangystay region & 0,215 (missing) & 0,272 (missing) \\
\hline South Kazakhstan region & 0,872 (missing) & 0,924 (missing) \\
\hline Pavlodar region & $-0,918$ (very high) & 0,907 (missing) \\
\hline North Kazakhstan region & $-0,934$ (very high) & 0,938 (missing) \\
\hline East Kazakhstan region & $-0,895$ (high) & $-0,847$ (high) \\
\hline Nur-Sultan city & $-0,745$ (high) & 0,688 (missing) \\
\hline Almaty city & 0,663 (missing) & 0,88 (missing) \\
\hline
\end{tabular}

Source: calculated by authors based on the data from the Committee on Statistics of the Ministry of National Economy of the Republic of Kazakhstan

As can be seen from Table 4, the environmental and economic situation in Kazakhstan in the context of regions is heterogeneous. For 2005-2018 gross domestic product growth rate in Kazakhstan at prices comparable to 2005 was $171.1 \%$, and the emission of solid pollutants into the air during the same period decreased by $28.8 \%$, and the emission of liquid and gaseous substances decreased by $14 \%$. In Kazakhstan as a whole, the emission of pollutants into the atmosphere tends to decrease. However, a general decrease in the volume of emissions of solid pollutants into the atmosphere is achieved due to 7 regions in which the effect of decoupling is observed, and in 4 regions (Almaty, Karaganda, Pavlodar, and North Kazakhstan regions) the effect is very high. The situation with emissions of liquid and gaseous pollutants into the atmosphere is worse than for emissions of solids. The decoupling effect is determined only in Aktobe, Almaty, West Kazakhstan, Karaganda, East Kazakhstan regions. It should be noted that in Almaty, East 
Kazakhstan and Karaganda regions there is a decoupling effect on emissions of both solid and gaseous pollutants.

According to table 4, in the largest center of coal mining in Kazakhstan - in the Karaganda region was revealed a high level of decoupling effect. For many years the region was the leader in terms of air emissions, however, over the period under review, it was possible to reduce atmospheric emissions of pollutants emanating from stationary sources by $58.5 \%$. The ArcelorMittal Temirtau company, which is the main environmental pollutant and contributes $77 \%$ of the air pollution of the Karaganda region, regularly reduces the amount of harmful substances into the atmosphere, but due to the operation of outdated equipment, the concentration of harmful emissions remains high.

One of the measures to reduce atmospheric air pollution is the Memorandum of Cooperation, signed between the Department of Natural Resources, Environmental Management and the Department of Ecology of the Karaganda region in order to reduce the environmental burden in terms of reducing the permitted emission standards for industrial enterprises of the Karaganda region, as well as an action plan aimed at reducing the permitted volume of emissions by The object II, III, IV categories was agreed on.

The "Green" Council of the Karaganda Region has created a comprehensive plan for improving the environmental situation of Temirtau for 2018-2020, which includes measures to reduce emissions into the atmosphere by large industrial enterprises through the reconstruction and construction of new dust and gas collecting equipment, modernization of production within the framework of environmental protection plans and measures aimed to increase energy conservation in the city.

Planned costs for the implementation of environmental projects, according to the Environmental Action Plan of ArcelorMittal Temirtau JSC for 2019-2021, amount to over 35 billion tenge. The costs of environmental projects in 2018 amounted to 9.7 billion tenge, bag filters were put into operation, which will reduce atmospheric emissions by 200 thousand tons per year, which is $1 / 3$ of all emissions of the Karaganda region (official website of JSC ArcelorMittal Temirtau).

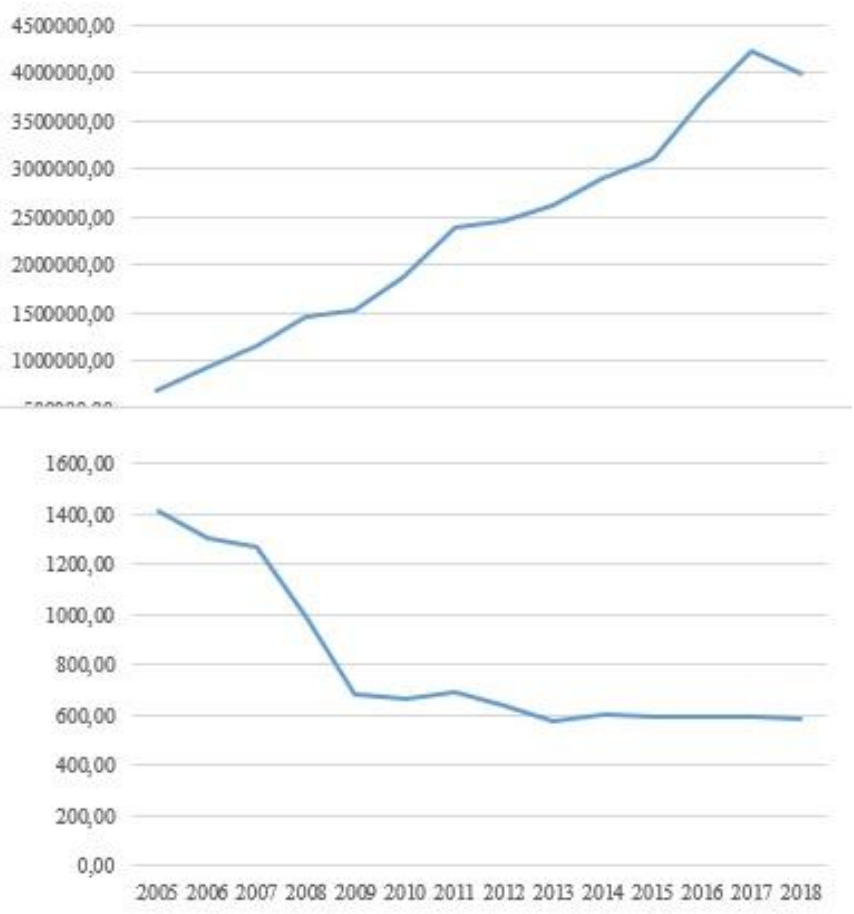

Figure 5. The effect of decoupling of the Karaganda region for 2005-2018

Source: compiled by authors 
The word "decoupling" means "untying, splitting, disconnecting, separation, communication failure". Therefore, the definition of decoupling is associated with a situation where two indicators have an inverse relationship. Figure 5 graphically shows the inverse relationship between GRP and atmospheric emissions of the Karaganda region.

Further, it is necessary to consider in detail the environmental and economic situation in the regions that showed the worst result when assessing the decoupling effect and identify the reason for the constant increase in pollutant emissions and the generally unavailability of the regions to transit to a green economy.

One of the regions of Kazakhstan that showed the worst result in assessing the decoupling effect is the Zhambyl region, which is famous for the chemical industry. At the end of 2016, the company "Kazphosphate" launched the production of phosphorus-potash fertilizers, as a result of which the production of chemical products in the region in 2018 reached 121 790,38 million tenge, and increased by $171 \%$ compared to 2016 . Along with an increase in production, emissions of pollutants into the atmosphere also increased by almost 10 thousand tons (124\%) over the past 2 years. The main share of pollutant emissions from stationary sources is in the chemical sector (42\%).

Let us consider the influence of the volume of production of the chemical industry on emissions of pollutants into the atmosphere for 2005-2018 in the form of a one-factor econometric model:

$$
\begin{aligned}
Y=6+0.0002 X, & R^{2}=0.91 \\
(2.61)(0.000015) &
\end{aligned}
$$

As a result of constructing a linear regression, it was found that in $91 \%$ of cases, a change in the volume of production of chemical products leads to a change in the volume of emissions of pollutants into the atmosphere. The constructed model is reliable, since the coefficients are statistically significant.

Over the past 5 years, about 50 industrial and processing enterprises have been opened in the region, among them the sodium cyanide production plant LLP "Talas Investment Company", JSC "Zhambylgips", "Taraz Chemical Park" Special Economic Zone, which implements 6 projects production of caustic soda, chlorine, phosphorus trichloride, glyphosate, pesticides, methanol.

As a result of the prosperity of the chemical industry for many years, today the environmental situation in the region has become critical. Many plants have sewage treatment and devices, but they cannot cope with such volumes of production. Some enterprises pay for the emission of air polluting substances. But this is not enough to solve environmental problems. Ecologists propose to oblige companies to switch to a closed production cycle, in which harmful substances are not released into the atmosphere in large quantities and it will help reduce emissions into the atmosphere by 10 times. This measure, in turn, will make it possible to achieve the decoupling effect between economic growth and its environmental impact.

Another region of Kazakhstan, in which the growth rate of GRP and atmospheric emissions of pollutants are directly dependent is the South Kazakhstan region. The main sources of air pollution in the region are stationary sources of pollutant emissions into the atmosphere of production facilities of oil refining enterprises. For 2005-2018 the growth rate of the production of oil products in the South Kazakhstan region in comparable prices to 2005 amounted to $198.6 \%$, and the emission of pollutants into the air during the same period increased by $172.3 \%$, this suggests that no absolute or relative decoupling effect.

The influence of the volume of oil refineries production and pollution emissions was estimated by constructing a pair linear regression model:

$$
Y=36.56+0.0004 X, \quad R^{2}=0.79
$$


As a result of building the model, we can conclude that in $79 \%$ of cases, a change in the volume of production of oil products leads to a change in the volume of emissions of pollutants into the atmosphere. The constructed model is reliable, since the equation of the model is qualitative in the Fisher distribution $\left(F_{s t}=45.43\right)$, and also by the Student criterion, the coefficients are statistically significant $\left(t_{b}=\right.$ $\left.7.02 ; t_{a}=13.25\right)$.

\section{CONCLUSIONS}

The purpose of the article was to assess the impact of existing measures aimed at reducing the environmental impact, in our case it's the Concept of transition to green economy, that adopted in Kazakhstan in 2013 and analysis of the situation in the context of the regions of Kazakhstan

We used the synthetic control method to assess the effect from adoption the Concept of transition to green economy in Kazakhstan. Using panel data of $\mathrm{CO}_{2}$ emissions, GDP per capita, GDP growth, Agriculture value added, Industry value added, Service value added, Urban population variables for Kazakhstan and 30 donor pool countries for 2003-2018, a counterfactual group was constructed, it allowed us to estimate volume of $\mathrm{CO}_{2}$ emissions that would have been in Kazakhstan if Kazakhstan had not adopted the Concept of transition to green economy. Our results show that $\mathrm{CO}_{2}$ emissions in Kazakhstan would have been higher without the adoption of the Concept, however, emissions are increasing every year.

The results of evaluating decoupling effect in the regions of Kazakhstan showed that the environmental situation in the country is not comforting. In 9 regions of the country, the effect of decoupling was not observed, that is, along with the growth of GRP, the volumes of emissions of pollutants also increase.

To achieve the effect of decoupling at the regional level, significant changes are required in a centralized state policy, patterns of behavior, and the pace of scientific and technological progress. As known, the main share of the economy of Kazakhstan is made up of sectors with a large environmental impact, and GDP growth is ensured by the extraction of minerals and manufacturing industries, and not by the production of science-intensive products. In this regard, the primary task is government support for R\&D and innovation, aimed at increasing the resource intensity and energy efficiency of production and modernization based on innovations aimed at meeting growing needs, while minimizing the impoverishment of natural capital.

\section{REFERENCES}

Abadie, A., Diamond, A., Hainmueller, J. (2010). Synthetic control methods for comparative case studies: estimating the effect of California's tobacco control program. Journal of the American Statistical Association, 105(490), 493505.

Abadie, A., Gardeazabal, J. (2003). The Economic Costs of Conflict: A Case Study of the Basque Country. American Economic Review, 93(1), 112-132.

Akizu-Gardoki, O., Bueno, G., Wiedmann, T., Lopez-Guede, J.M., Arto, I., Hernandez, P., Moran, D. (2018). Decoupling between human development and energy consumption within footprint accounts. Journal of Cleaner Production, 202, 1145-1157. doi: 10.1016/j.jclepro.2018.08.235.

Aytug H., Kutuk M.M., Oduncu A., Togan S. (2017) Twenty Years of the EU-Turkey Customs Union: A Synthetic Control Method Analysis. Journal of Common Market Studies, 55 (3), 419-431, doi: 10.1111/jcms.12490

Bilan, Yu., Streimikiene, D., Vasylieva, T., Lyulyov, O., Pimonenko, T., Pavlyk, A. (2019). Linking between Renewable Energy, $\mathrm{CO}_{2}$ Emissions, and Economic Growth: Challenges for Candidates and Potential Candidates for the EU Membership. Sustainability, 11, 1528. doi:10.3390/su11061528.

Bluszcz, A. (2019). Decoupling Economic Growth from Emissions in Poland on the Background of EU Countries. IOP Conference Series: Earth and Environmental Science. doi: 10.1088/1755-1315/221/1/012119. 
Bobylev, S.N., Zakharov, V.M. (2012). Green economy and modernization. Ecological and economic foundations of sustainable development. Bulletin of the Institute of Sustainable Development of the RF Civic Chamber «Towards a Sustainable Russia), 60, 62-74.

EDGARv5.0 Report (Emissions Database for Global Atmospheric Research) (2019). EU Science Hub, European Commission, https://edgar.jrc.ec.europa.eu/overview.php?v=50_GHG.

German Development Institute (2009). Sustainability-oriented Innovation Systems. Towards Decoupling Economic Growth from Environmental Pressures?. Discussion Paper. ISSN 1860-0441.

Jardon, A., Kuik, O., Tol, R.S.J. (2020). Causal effects of PetroCaribe on sustainable development: a synthetic control analysis. The Manchester School, 88(1), 156-210. doi: 10.1111/manc.12275.

Jiborn, M., Kander, A., Kulionis, V., Nielsen, H., Moran, D.D. (2018). Decoupling or delusion? Measuring emissions displacement in foreign trade. Global Environmental Change, 49, 27-34. doi: 10.1016/j.gloenvcha.2017.12.006.

Jonek-Kowalska, I. (2019). Transformation of energy balances with dominant coal consumption in European economies and Turkey in the years 1990-2017. Oeconomia Copernicana, 10(4), 627-647. doi: 10.24136/oc.2019.030.

Jonek-Kowalska, I. (2017). Coal mining in Central-East Europe in perspective of industrial risk. Oeconomia Copernicana, 8(1), 131-143. doi: 10.24136/oc.v8i1.9.

Kiseláková, D., Šofranková, B., Onuferová, E., \& Čabinová, V. (2019). The evaluation of competitive position of EU28 economies with using global multi-criteria indices. Equilibrium. Quarterly Journal of Economics and Economic Policy, 14(3), 441-462. doi: 10.24136/eq.2019.021.

Limareva, D.A. (2013) Decoupling as a factor in resolving the contradiction between population growth and the implementation of the green economy concept. Electronic Journal SCI-ARTICLE.RU, 2.

Liao, H., Long, Y., Ming, T., Mardani, A., Xu, J. (2019). Low carbon supplier selection using a hesitant fuzzy linguistic span method integrating the analytic network, Transformations in Bussiness and Economics, 18 (2(47)), 67-88.

Mikayilova, J.I., Hasanova, F.J., Galeottif, M. (2018). Decoupling of $\mathrm{CO}_{2}$ emissions and GDP: A time-varying cointegration approach. Ecological Indicators, 95, 615-628. doi: 10.1016/j.ecolind.2018.07.051.

Moreau, V., De Oliveira Neves C.A., Vuille F. (2019). Is decoupling a red herring? The role of structural effects and energy policies in Europe. Energy Policy, 128, 243-252. doi: 10.1016/j.enpol.2018.12.028.

Moreau, V., Vuille F. (2018). Decoupling energy use and economic growth: Counter evidence from structural effects and embodied energy in trade. Applied Energy, 215, 54-62. doi: 10.1016/j.apenergy.2018.01.044.

Mukhtarova, K.S., Trifilova, A.A., Zhidebekkyzy, A. (2016). Commercialization of Green Technologies: an Exploratory Literature Review. Journal of International Studies, 9(3), 75-87. doi: 10.14254/2071-8330.2016/9-3/6.

Mukhtarova, K.S., Zhidebekkyzy, A. (2015). Development of Green Economy via Commercialization of Green Technologies: Experience of Kazakhstan. Journal of Asian Finance, Economics and Business, 2(4), 21-29. doi: 10.13106/jafeb.2015.vol2.no4.21.

Official website of JSC Arcelor Mittal Temirtau https://www.arcelormittal.kz/index.php?id=10\&pr=154.

Official website of the Committee on Statistics of the Ministry of National Economy of the Republic of Kazakhstan http://stat.gov.kz/.

Razminiene, K. (2019). Circular economy in clusters' performance evaluation. Equilibrium. Quarterly Journal of Economics and Economic Policy, 14(3), 537-559. doi: 10.24136/eq.2019.026.

Samarina, V.P., Skufina, T.P. (2015) "Green economy" of mining regions of Russia: facts and trends. Mining Information and Analytical Bulletin, special issue, 267-272.

Sansyzbayeva, K.N., Zhidebekkyzy, A. (2016). Agricultural Innovations for Sustainable Development: Analysis of Situation in Kazakhstan and Ways for Improvement. International Conference on Business and Economics.

Savitz, R., Gavriletea, M.D. (2019), Climate Change and Insurance, Transformations in Business \& Economics, Vol. 18, No 1 (46), pp.21- 43.

Stamm, A., Dantar, E., Fisher, D., Ganguly, S., Rennkamp, B. (2009). Sustainabity-oriented innovation systems. Towards decoupling economic growth from environmental pressures. DIE Research Project "Sustainable solutions through research". Deutsches Institut fur Entwicklungspolitik.

UN (2008). Report of the Joint UNECE/OECD/Eurostat Working Group on Statistics for Sustainable Development. New York and Geneva. 
Vasylieva, T., Lyulyov, O., Bilan, Y., Streimikiene. D. (2019). Sustainable Economic Development and Greenhouse Gas Emissions: The Dynamic Impact of Renewable Energy Consumption, GDP, and Corruption. Energies, 12, 3289. doi:10.3390/en12173289.

World Development Indicators of World Bank. Available at: http://datatopics.worldbank.org/world-developmentindicators/themes/economy.html

Wu, Y., Zhu, Q., Zhu B. (2018). Decoupling analysis of world economic growth and $\mathrm{CO}_{2}$ emissions: A study comparing developed and developing countries. Journal of Cleaner Production, 190, 94-103. doi: 10.1016/j.jclepro.2018.04.139.

Yashalova, N.N. (2015). The use of correlation analysis in environmental and economic research. Environmental Economics, 6.

Yu, X., Shen, M., Wang, D., Imwa, B.T. (2019). Does the Low-Carbon Pilot Initiative Reduce Carbon Emissions? Evidence from the Application of the Synthetic Control Method in Guangdong Province. Sustainability, 11, 3979. doi:10.3390/su11143979.

Zhidebekkyzy, A., Trifilova, A., Sansyzbayeva, G.N. (2019). Organizational and economic mechanisms for commercialization of green technologies in Kazakhstan. The Journal of Economic Research \& Business Administration, 1(127), 13-21. 